\title{
Pneumonitis after inhalation of mercury vapours
}

\author{
JD Glezos MD FRCPC ${ }^{1}$, JE Albrecht MD², RD Gair BSc (Pharm) ${ }^{3}$
}

\begin{abstract}
JD Glezos, JE Albrecht, RD Gair. Pneumonitis after inhalation of mercury vapours. Can Respir J 2006;13(3):150-152.

A 43-year-old man presented to hospital with pneumonia but only after discharge from hospital did he admit to deliberate prior inhalation of mercury. His pulmonary involvement appeared to resolve almost completely with antibiotics and supportive care. Nevertheless, persisting elevated urinary excretion of mercury required two courses of chelation therapy. No serious systemic sequelae were observed.
\end{abstract}

Key Words: Chelation therapy; Inhalation exposure; Mercury poisoning; Pneumonia; Succimer

$\mathrm{M}$ ercury exists in three forms: elemental mercury occurs naturally in the earth's crust as a silver-coloured liquid; inorganic salts such as cinnabar and calomel are found as ores; and organic compounds are formed after deposition of atmospheric mercury into water bodies (1). Inhalation of mercury vapour is extremely dangerous. Such exposures usually occur accidentally in occupational settings or following improper home use (2). We report a case of nonfatal pneumonitis following intentional inhalation of elemental mercury vapour. The pulmonary infiltrates resolved rapidly with antibiotics and supportive care. Surprisingly, the patient did not admit to mercury vapour inhalation until after his discharge from hospital, and only then because he was concerned about possible long-term effects.

\section{CASE PRESENTATION}

A 43-year-old, $70 \mathrm{~kg}$ man was admitted to hospital with a six-day history of cough, pyrexia, rigors, pharyngitis and nausea, as well as back and epigastric pain. During that time, he had visited another emergency department on two occasions, where he was treated as an outpatient with azithromycin and then switched to levofloxacin because of recurrent emesis. Past history included 25 pack-years of smoking, chronic obstructive pulmonary disease, hyperlipidemia and myocardial infarction. Medications included sporadic fluticasone and salbutamol. Three months previously, he had been assessed for gambling addiction and suicidal ideation. He denied illicit drug use or homosexual activity. He worked as a pipefitter and he had not recently travelled.

Physical examination on admission revealed an ill-looking man in the fetal position with a temperature of $39.8^{\circ} \mathrm{C}$, blood pressure of $114 / 78 \mathrm{mmHg}$, a heart rate of 116 beats/min and mild dyspnea with $\mathrm{O}_{2}$ saturation $98 \%$ on room air. Oral mucous membranes were dry with marked gingivitis. A generalized maculopapular rash was noted, especially over his trunk. A $1 \mathrm{~cm}$ tender lymph node was present in the left axilla. His lungs

\section{Une pneumonite après l'inhalation de vapeurs de mercure}

\begin{abstract}
Un homme de 43 ans s'est présenté à l'hôpital atteint de pneumonie, mais ce n'est qu'après son congé de l'hôpital qu'il a admis avoir délibérément inhalé du mercure avant sa consultation. Son atteinte pulmonaire semble s'être résolue presque complètement à l'aide d'antibiotiques et de soins de soutien. Néanmoins, une excrétion élevée de mercure persistante dans l'urine a exigé deux cures de traitement par chélation. Aucune séquelle systémique grave n’a été observée.
\end{abstract}

were free of any adventitious sounds. He appeared quite withdrawn and vague but had no other neurological deficits. A chest $\mathrm{x}$-ray revealed bilateral lower lobe infiltrates (Figure 1).

Laboratory results including serum urea and creatinine, leukocytes, ferritin, packed cell volume, random glucose and bilirubin were normal. The patient's hemoglobin level was $114 \mathrm{~g} / \mathrm{L}$ (normal range $135 \mathrm{~g} / \mathrm{L}$ to $180 \mathrm{~g} / \mathrm{L}$ ), his serum albumin level was $26 \mathrm{~g} / \mathrm{L}$ (normal range $35 \mathrm{~g} / \mathrm{L}$ to $50 \mathrm{~g} / \mathrm{L}$ ), his eosinophil count was $0.9 \times 10^{9} / \mathrm{L}$ (normal range less than $0.7 \times 10^{9} / \mathrm{L}$ ) and he showed grade $2+$ reactive lymphocytosis. His serum sodium was $132 \mathrm{mmol} / \mathrm{L}$ (normal range $135 \mathrm{mmol} / \mathrm{L}$ to $145 \mathrm{mmol} / \mathrm{L}$ ). Liver function tests were normal on admission, with the exception of his gamma-glutamyltransferase level, which was mildly elevated at $62 \mathrm{U} / \mathrm{L}$ (normal range less than $49 \mathrm{U} / \mathrm{L}$ ). Later, during his hospital stay, he experienced a minor elevation of other liver enzymes. A hepatitis screen was nonreactive for antihepatitis B and antihepatitis C virus. HIV and syphilis serology were nonreactive. Sputum culture grew grade $3+$ respiratory flora and a blood culture showed no growth.

The patient was treated with intravenous fluids and cefuroxime, plus oral clarithromycin. Over the next few days, his fever, rash and gingivitis subsided. A chest $\mathrm{x}$-ray performed a few days after admission showed considerable clearing of the infiltrates (Figure 2). He was discharged one week after admission.

Approximately one week after discharge, the patient admitted to his family doctor that he had deliberately ingested a 'few sips' of liquid mercury approximately one week before the onset of his illness. He had also heated up a container of liquid mercury and inhaled the vapours on at least three occasions over a period of two to three days during this time. Within $2 \mathrm{~h}$ to $3 \mathrm{~h}$ of inhalation, he experienced flu-like symptoms with fever, cough and myalgia. He became polydypsic with a reduction in his urine output. He also observed mercury in his stools. A $24 \mathrm{~h}$ sample of urine collected approximately five

${ }^{1}$ Division of Respiratory and Critical Care Medicine, Department of Internal Medicine; ${ }^{2}$ Department of General Practice, Royal Columbian

Hospital, New Westminster; ${ }^{3}$ BC Drug and Poison Information Centre, Vancouver, British Columbia

Correspondence: Dr JD Glezos, 103 - 250 Keary Street, New Westminster, British Columbia V3L 5E7. Telephone 604-525-8822,

fax604-525-9470,e-mail jamesglezos@yahoo.com 


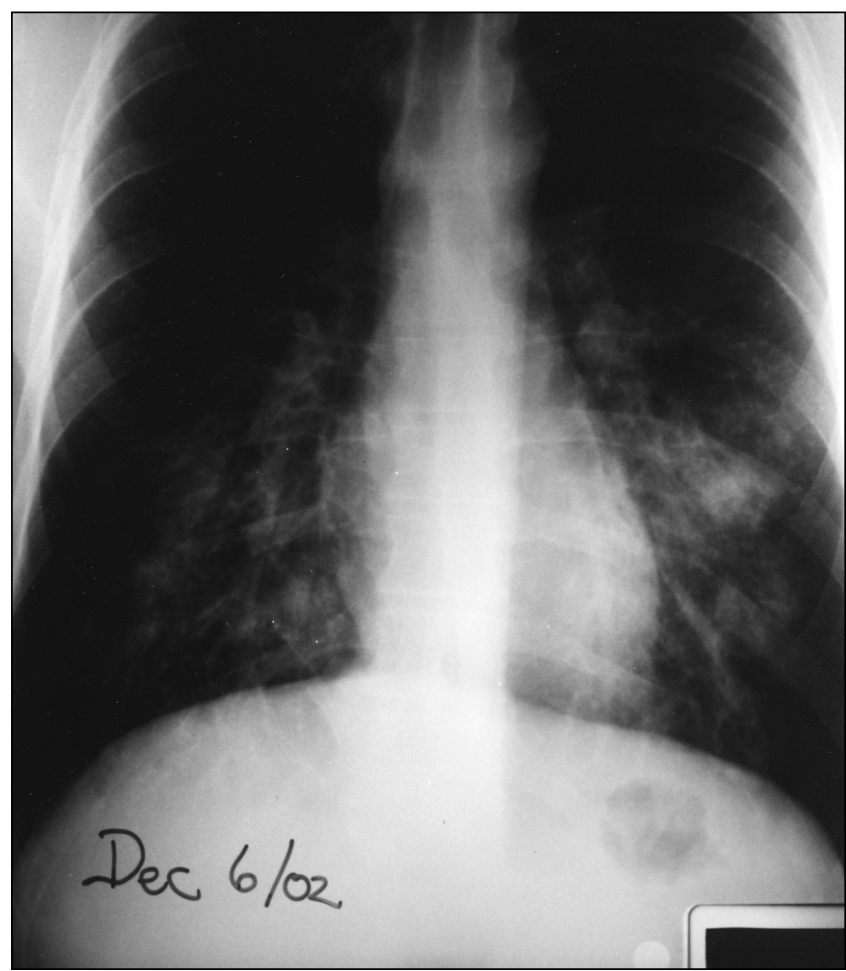

Figure 1) Chest $x$-ray on admission

weeks following the event measured $970 \mathrm{nmol} / \mathrm{L}$ mercury (normal range less than $250 \mathrm{nmol} / \mathrm{L}$ ). The patient was treated with succimer (Chemet, Ovation Pharmaceuticals, USA) $700 \mathrm{mg}$ $(10 \mathrm{mg} / \mathrm{kg}$ ) orally every $8 \mathrm{~h}$ for five days and then $700 \mathrm{mg}$ every $12 \mathrm{~h}$ for an additional 14 days.

Blood work repeated after completion of the first course of succimer, including a complete blood count with differential and liver function tests, was found to be normal. The serum creatinine level was mildly elevated to $109 \mu \mathrm{mol} / \mathrm{L}$ (normal range $45 \mu \mathrm{mol} / \mathrm{L}$ to $100 \mu \mathrm{mol} / \mathrm{L})$. Twenty-four hour urinary mercury excretion was $265 \mathrm{nmol} / \mathrm{L}$ and a second course of succimer was initiated.

A high-resolution computed tomography scan of the chest showed resolution of the previously noted lower lobe consolidation, with no evidence of diffuse interstitial lung disease. Pulmonary function tests two months after admission showed mild air flow limitation, with improvement after treatment with a bronchodilator: prebronchodilator forced expiratory volume in $1 \mathrm{~s}\left(\mathrm{FEV}_{1}\right)$ was $3.65 \mathrm{~L}$ (93\%), postbronchodilator $\mathrm{FEV}_{1}$ was $4.33 \mathrm{~L}(111 \%), \mathrm{FEV}_{1} /$ forced vital capacity was $68 \%$, forced expiratory flow at $50 \%$ of vital capacity was $2.86 \mathrm{~L} / \mathrm{s}(58 \%)$, total lung capacity was $8.2 \mathrm{~L}(119 \%)$, residual volume/total lung capacity was $117 \%$ and reduced diffusion capacity was $20.63 \mathrm{~mL} / \mathrm{min} / \mathrm{mmHg}(65 \%)$. Pulmonary function tests repeated 28 months later showed very little change, including a diffusion capacity of $21.19 \mathrm{~mL} / \mathrm{min} / \mathrm{mmHg}(67 \%)$.

After a second course of succimer, the patient's 24 h urinary mercury excretion normalized to $29 \mathrm{nmol} / \mathrm{L}$. No further treatment was provided. During the chelation period (longer than six weeks), the patient remained asymptomatic with no respiratory or neurological sequelae, even after 18 months of follow-up. The local public health authority conducted an on-site inspection of his residence and found traces of mercury on a propane bottle nozzle in the garage and near a stove fan in the kitchen.

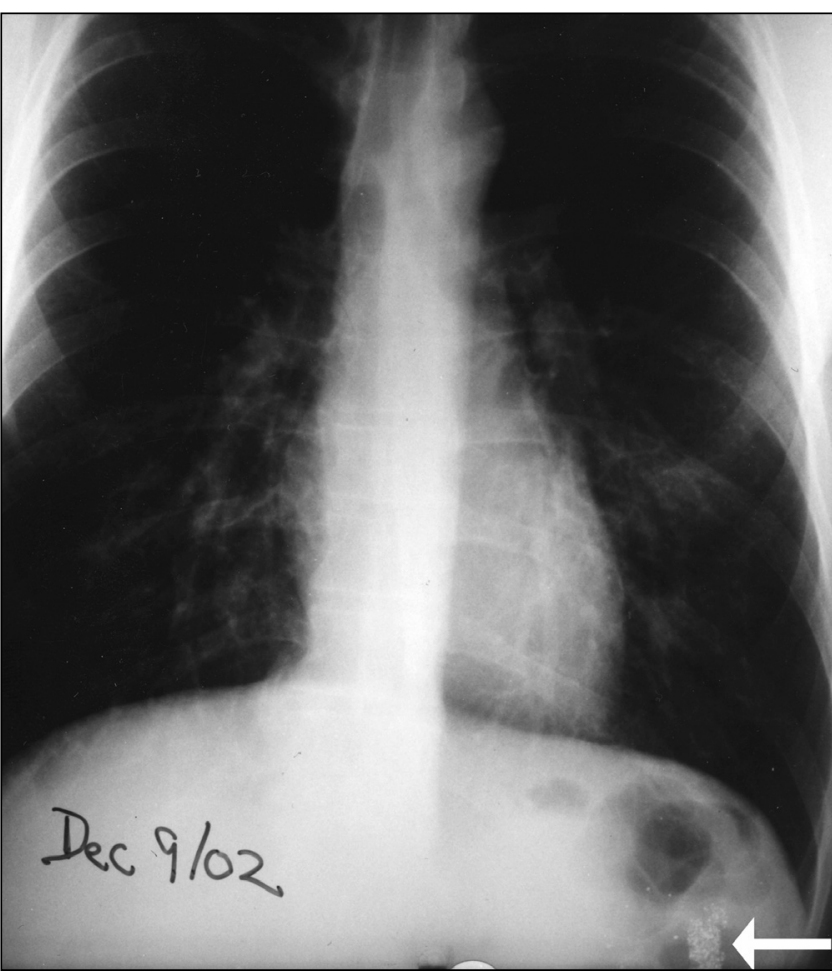

Figure 2) Rapid partial clearing of infiltrates noted within three days of admission. Note the radiodense material located in the splenic flexure (arrow)

\section{DISCUSSION}

Mercury disrupts normal cell physiology in a variety of organ systems, primarily through covalent binding to intracellular sulfhydryl-containing enzymes and proteins (1). The ingestion of elemental mercury normally causes minimal toxicity because of poor gut absorption. Inhalation of elemental mercury vapour, however, may cause serious outcomes, including death. The pulmonary system and central nervous system (CNS) are the primary targets for toxicity following this route of exposure. Thermal damage to lung tissue occurs from inhalation of high temperature vapour and oxidized mercury ions cause direct airway irritation and cellular toxicity $(3,4)$. Mercury crosses the alveolar membrane during respiration, leading to rapid systemic absorption and wide distribution into tissues. Large acute exposures to elemental mercury may cause significant accumulation in the CNS within a few days (1). Oxidation of elemental mercury to the toxic mercuric ion in the CNS and other tissues is responsible for the manifestations of mercury poisoning. Excretion occurs in the urine and feces, with an elimination half-life of 30 to 60 days.

The clinical syndrome of acute mercury vapour inhalation has been described in three phases $(2,3)$. Within a few hours, patients typically experience cough, fever, shortness of breath, headache and muscle aches. Gastrointestinal complaints include salivation, sore throat, gingivitis, abdominal pain and diarrhea. Over the next few days, the second phase is dominated by pulmonary complications, including interstitial pneumonitis, bilateral infiltrates, noncardiogenic pulmonary edema and acute respiratory distress. Pneumatoceles, interstitial emphysema, pneumomediastinum and pneumothorax have also been reported (5). Death may occur from progressive hypoxia. In survivors, the late phase is characterized by symptoms associated with chronic mercury inhalation or exposure to inorganic 
mercury. Gingivostomatitis is common, along with CNS manifestations such as tremors and erethism (shyness, withdrawal, depression, insomnia and irritability) (3). Chest $\mathrm{x}$-rays often show diffuse, patchy changes of pulmonary edema, which usually clear but may progress to interstitial fibrosis, pulmonary granulomas and bronchiectasis $(1,6,7)$. Pulmonary function tests may show a mixture of restrictive and obstructive defects $(6,7)$.

The management of acute mercury vapour inhalation centres on the maintenance of respiratory function with oxygen, bronchodilators, mechanical ventilation, if necessary, and evaluation of systemic absorption $(1,3)$. Whole blood mercury levels accurately assess toxicity in recent exposures, but do not measure total body burden in chronic exposures or exposures that have occurred more than a few days prior (3). Timed, $24 \mathrm{~h}$ urinary collections provide a more accurate measure of total body burden and are useful for assessing chelation therapy. Significant clinical symptoms are usually associated with $24 \mathrm{~h}$ urine concentrations greater than $250 \mathrm{nmol} / \mathrm{L}(2,8)$. Succimer, an orally administered analogue of dimercaprol (British AntiLewisite), is an effective chelator for patients with elevated mercury excretion and is currently favoured because it is better tolerated than British Anti-Lewisite and easier to administer (3).

Our patient exhibited many of the symptoms associated with acute exposure to mercury vapours, including rigors,

\section{REFERENCES}

1. Sue Y-J. Mercury. In: Goldfrank LR, Flomenbaum NE, Lewin NA, et al, eds. Goldfrank's Toxicologic Emergencies, 7th edn. New York: McGraw-Hill, 2002:1239-48.

2. Solis MT, Yuen E, Cortez PS, Goebel PJ. Family poisoned by mercury vapor inhalation. Am J Emerg Med 2000;18:599-602.

3. Dart RC, Sullivan JB. Mercury. In: Dart RC, ed. Medical Toxicology, 3rd edn. Philadelphia: Lippincott Williams \& Wilkins, 2004:1437-48.

4. Rowens B, Guerrero-Betancourt D, Gottlieb CA, Boyes RJ, Eichenhorn MS. Respiratory failure and death following acute inhalation of mercury vapor. A clinical and histologic perspective. Chest 1991;99:185-90. pharyngitis and respiratory distress. He also showed signs of chronic mercury exposure, such as gingivitis and a peculiar withdrawn demeanour. Pulmonary function findings of air flow limitation and hyperinflation were likely the result of his smoking history, although the high-resolution computed tomography scan showed no obvious emphysema. In addition, the lack of improvement in the reduced diffusion capacity more than two years after the exposure makes it less likely to be due to mercury pneumonitis (9). His urine mercury excretion remained well within the toxic range five weeks after his exposure and he required two courses of succimer over a six-week period before it normalized. He has been followed for some 28 months without any further complications noted.

Clues to the correct diagnosis in our patient included his previous psychiatric history, his occupation and accessibility to chemicals, the gingivitis and abdominal complaints, his withdrawn behaviour, the radiodense material in his gut and the radiological course showing rapid clearing of the parenchymal infiltrates. Although spontaneous improvement of chemical pneumonitis had occurred before chelation was initiated, this treatment was nevertheless indicated in an attempt to prevent sequelae associated with mercury poisoning. Remarkably, he showed little, if any, sequelae.

5. Bates BA. Mercury. In: Haddad LM, Shannon MW, Winchester JF, eds. Clinical Management of Poisoning and Drug Overdose, 3rd edn. Philadelphia: WB Saunders Co, 1998:750-6.

6. Lilis R, Miller A, Lerman Y. Acute mercury poisoning with severe chronic pulmonary manifestations. Chest 1985;88:306-9.

7. Morgan WK, Seaton A. Occupational Lung Diseases, 3rd edn. Philadelphia: WB Saunders Co, 1995:590.

8. Clarkson TW. Human toxicology of mercury. J Trace Elem Exp Med 1998;11:303-17.

9. Fraser RS, Muller NL, Colman N, Paré PD, eds. Fraser and Paré's Diagnosis of Diseases of the Chest, 4th edn. Philadelphia: WB Saunders Co, 1999:2527. 


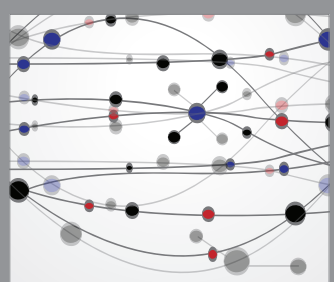

The Scientific World Journal
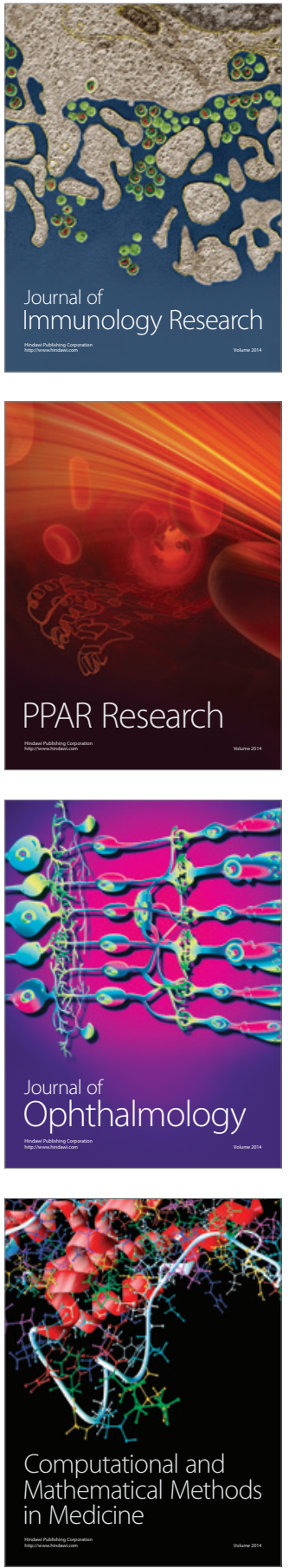

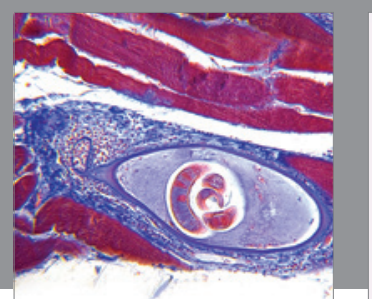

Gastroenterology Research and Practice

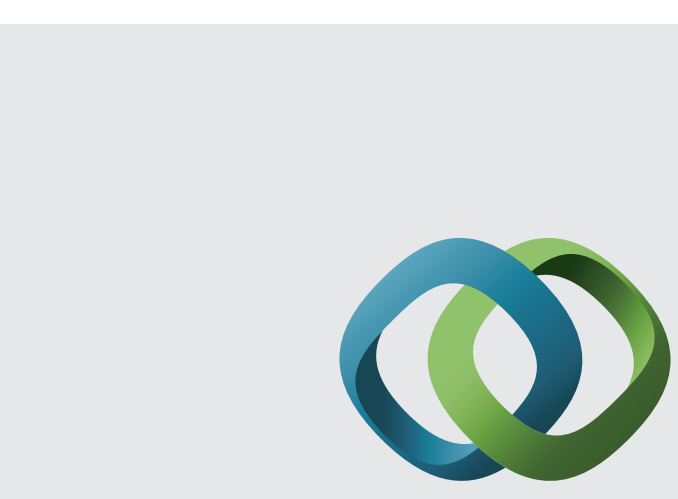

\section{Hindawi}

Submit your manuscripts at

http://www.hindawi.com
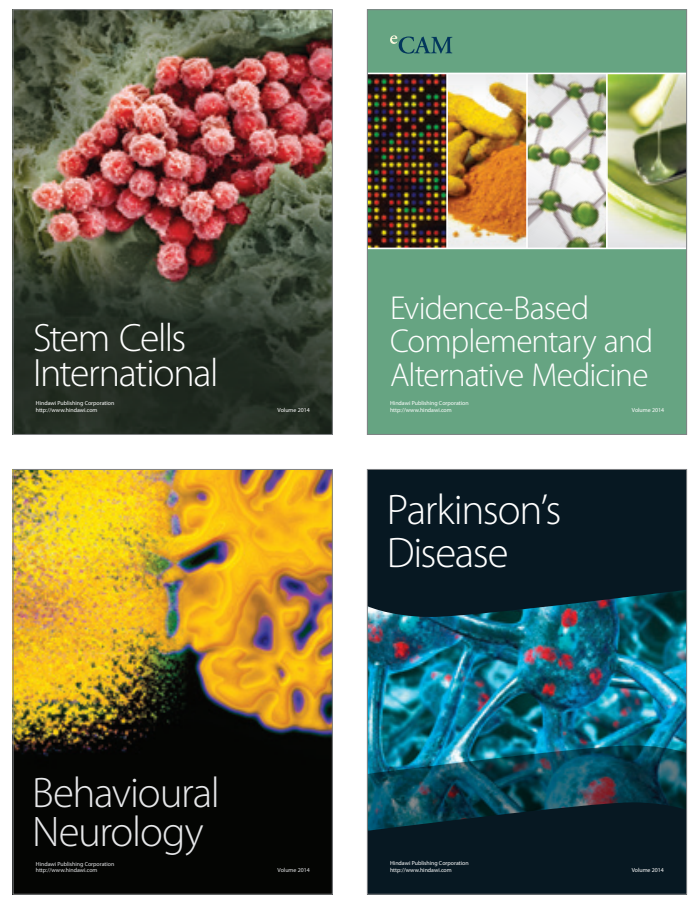
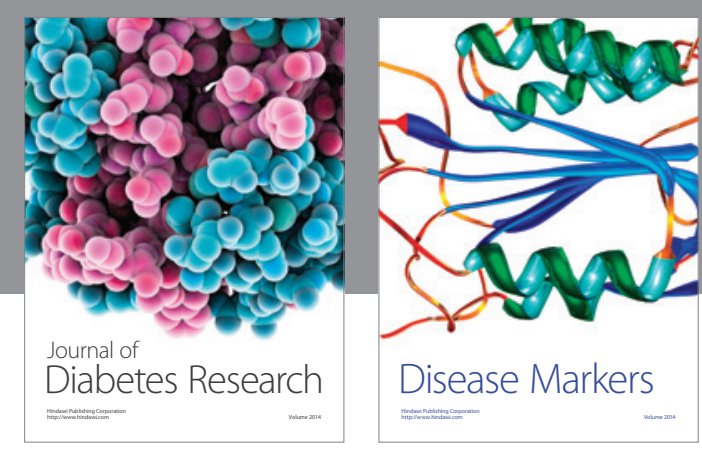

Disease Markers
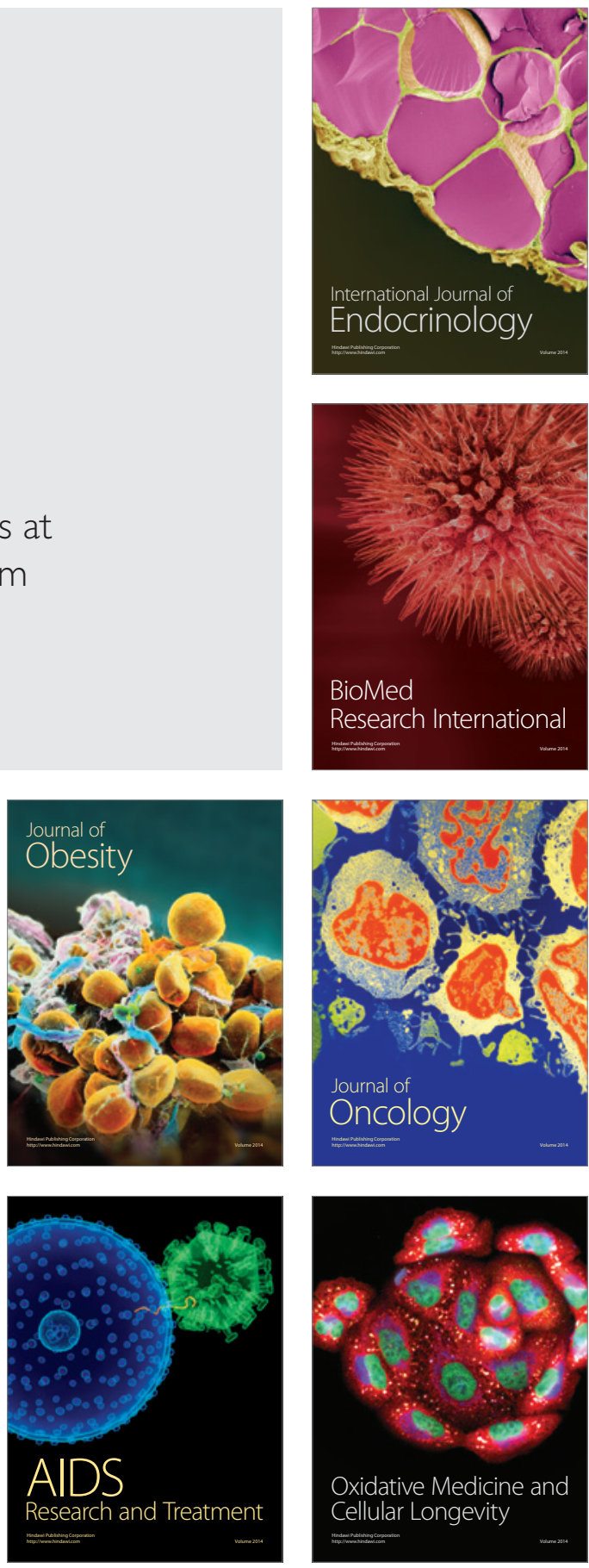